\title{
Platinum Drug Sensitivity Polymorphisms in Stage III Non-small Cell Lung Cancer With Invasion of Mediastinal Lymph Nodes
}

\author{
ANCA NASTASE ${ }^{1}$, AUDREY LUPO ${ }^{2}$, VICTORIA LASZLO ${ }^{1}$, DIANE DAMOTTE ${ }^{2}$, \\ SIMONA DIMA ${ }^{1}$, EMELYNE CANNY $^{2}$, MARCO ALIFANO ${ }^{2}$, \\ IRINEL POPESCU $^{1}$, WALTER KLEPETKO ${ }^{3}$ and MADALINA GRIGOROIU ${ }^{1}$ \\ ${ }^{1}$ Center of Digestive Diseases and Liver Transplantation, Fundeni Clinical Institute, Bucharest, Romania; \\ ${ }^{2}$ Department of Pathology, Hôpital Cochin, AP-HP, Université de Paris, Paris, France; \\ ${ }^{3}$ Department of Thoracic Surgery, Vienna General Hospital, Vienna, Austria
}

\begin{abstract}
Background/Aim: Patients with stage IIIA (N2) non-small cell lung cancer (NSCLC) with no progression after induction chemotherapy are usually selected for surgery. Nowadays, response to chemotherapy is not predictable. We aimed to identify genomic predictive markers for response to induction chemotherapy in stage IIIA (N2) NSCLC patients. Patients and Methods: Whole-exome sequencing (WES) was performed on samples from 11 patients with no response after induction chemotherapy and 6 patients with documented pathological response, admitted to the Hotel Dieu Hospital, Paris or Allegemeines Krakenhaus University, Vienna. Results: A higher alternative allele frequency was found on SENP5, rs63736860, rs 1602 and NCBP2, rs553783 in the nonresponder group, and on RGP1, rs1570248, SLFN12L, rs2304968, rs9905892, and GBA2, rs3833700 in the responder group. Conclusion: These polymorphisms contribute to interindividual sensibility to chemotherapy response. Interrogation of these genetic variations may have potential applicability when deciding the treatment strategy for patients with stage III NSCLC (N2).
\end{abstract}

Patients with non-small cell lung cancer (NSCLC) stage IIIA, with invasion of mediastinal lymph nodes (N2),

This article is freely accessible online.

Correspondence to: Madalina Grigoroiu, MD, Ph.D., Fundeni Clinical Institute, Fundeni Ave, No. 258, 022328 Bucharest, Romania. Tel: +40 213180417, Fax: +40 213180417, e-mail madalinalidia@yahoo.com

Key Words: Whole-exome sequencing, platinum sensitivity, NSCLC. represent about $25 \%$ of total NSCLC diagnosed cases (1). Chemotherapy is one of the main treatment options for these patients, followed by surgery if patients can tolerate it and are at least stabilized by the induction chemotherapeutic regimen. In patients with unresectable disease and without progression after chemotherapy the more recently addition of durvalumab demonstrated in the PACIFIC trail showed improved progression-free survival and overall survival (2) proving the benefit of checkpoint inhibitors in NSCLC stage III patient therapy.

The most common type of platinum salts used in NSCLC chemotherapy are cisplatin and carboplatin. They have different toxicity profiles, but cisplatin showed a better rate of objective response (3).

The mechanism of action of cisplatin is mediated by cisplatin-DNA adducts that interferes with the DNA repair mechanism of the cell eventually leading to cell apoptosis (4). The response to chemotherapy cannot be predicted by clinical methods, although pharmacogenomics studies are identifying SNPs that might estimate drug therapeutic effects. So far, studies that focused on finding predictive biomarkers for NSCLC stage IIIA (N2) patients' response to platinum chemotherapy, were mainly limited to genetic variations in genes known to be associated with platinum metabolism or DNA repair. These two mechanisms are known to be primarily affected by chemotherapy treatment. Fewer studies were directed to identifying polymorphisms in other genes, that might predict the sensitivity or resistance to therapy.

In this study, we aimed to identify differences in the molecular profiles between NSCLC stage IIIA (N2) responders and non-responders to chemotherapy (cisplatin/carboplatin) with emphasis in finding predictive variants in new genes, using whole-exome sequencing (WES). 


\section{Patients and Methods}

The design of the study was previously published in extenso (5). Below, we describe its most important points.

Patient groups. The study flowchart is shown in Figure 1A. Briefly, 73 patients admitted to Hotel Dieu Hospital in Paris and Allegemeines Krakenhaus in Vienna, with diagnosis of or suspected to have NSCLC, clinical stage IIIA (N2) were prospectively included in the study, between January 2011 and December 2012, based on a written informed consent. All patients had either mediastinoscopy or thoracoscopy in order to confirm the mediastinal lymph nodes invasion. After histological examination of the lymph node status, 44 patients were excluded from the study. Causes of exclusion are shown in Figure 1A. Only samples with more than $70 \%$ cellularity were considered for the genomic analysis. The remaining 29 patients received induction chemotherapy, based on one platinum salt (cisplatin or carboplatin) in association with a second chemotherapeutic agent. We excluded one patient who died after the first cure of chemotherapy, because of chemotherapy toxicity. After induction chemotherapy, the patients with clinical response according to WHO criteria were referred to surgical treatment.

"Non-responder" patients (group A) were considered those with no clinical response to induction chemotherapy and who finally were not referred for surgical resection and patients with clinical response to induction chemotherapy according to WHO criteria, but persistent $\mathrm{N} 2$ status on pathological examination of the resected lymph nodes after lung surgery. The "responders" patients (group B) were patients with no residual disease in the mediastinal lymph nodes on pathological examination after radical lymphadenectomy performed at lung surgery (down-staging). After surgical treatment, there were 21 patients in the "non-responders" group (group A) and 7 patients in the "responders" group (group B). Only tumour mediastinal lymph node (N2) samples before induction chemotherapy were analyzed in this study. Finally, 17 patients (11 patients in "non-responders" group and 6 patients in "responders" group) had tumor samples that fulfill the quality criteria required for whole exome sequencing (WES). The average sequencing depth on target and the total number of SNP obtained on each sample are shown in Table I.

DNA extraction. DNA was extracted from fresh-frozen tissue with a DNA extraction kit (Stratagene, San Diego, CA, USA) or QIAamp DNA Mini Kit (Qiagen, Hilden, Germany) according to the manufacturer's instructions. DNA concentration and integrity was checked with a Nanodrop ND 1000 and Qubit 2.0 fluorimeter and by gel electrophoresis in $1 \%$ agarose.

DNA sequencing. Whole-exome sequencing (WES) was performed at the Beijing Genomics Institute (BGI, PR China). Genomic DNA was hybridized using Sure Select Target Enrichment system (Agilent, Santa Clara, CA, USA) at 50X on an Illumina HiSeq2000 platform according to manufacturer protocol. BWA (BurrowWheeler Aligner) alignment and genome build 37 (hg19) was used to generate Bam files for data processing and finally for variant calling. Picard was used for removal of PCR duplicates. SNPs were called with Soaps, InDels with Samtools/GATK and SNVs with Varscan. Variant annotation was done using ANNOVAR for the confident variants.
Table I. Parameters of whole exome sequencing (WES) showing the average sequencing depth on target (at least 50X) and number of SNPS detected in each sequenced sample.

\begin{tabular}{lccc}
\hline Group & Sample & $\begin{array}{c}\text { Average sequencing } \\
\text { depth on target }\end{array}$ & $\begin{array}{c}\text { Total number } \\
\text { of SNPs }\end{array}$ \\
\hline A & 11B00790 & 50.72 & 79,698 \\
A & 11B02967 & 57.72 & 78,338 \\
A & LYN84 & 65.56 & 84,592 \\
A & LYN77_1 & 60.65 & 81,344 \\
A & 12B05696 & 58.44 & 80,321 \\
A & 11B04855 & 57.23 & 87,236 \\
A & 11B02702 & 66.19 & 80,081 \\
A & 11B3023 & 68.76 & 78,202 \\
A & 11B2941 & 66.86 & 84,410 \\
A & LYN72_1 & 56.25 & 74,755 \\
A & 11B05089 & 68.14 & 81,449 \\
B & 11B00602 & 65.67 & 74,452 \\
B & 12B3843 & 64.8 & 84,547 \\
B & LYN43_1 & 63.28 & 76,863 \\
B & LYN48_1 & 58.82 & 81,829 \\
B & LYN101_1 & 65.66 & 86,017 \\
B & 11B01622 & 65.85 & 78,490 \\
\hline
\end{tabular}

Data analysis. Our analysis aimed in identifying differences between group A and group B of patients looking at all identified variants. All variants were merged for all analyzed samples and the frequencies of reference allele and variant allele were calculated. Next, two by two tables were generated for the reference and variant allele in group A and group B and Fisher's exact test was used to calculated significance value ( $\mathrm{R}$ package). Analysis of linkage disequilibrium was done using the LDmatrix module from LDlink (6), in European populations. Statistical analysis and graphs were done with R Studio 3.5.2 or GraphPad Prism 7 (GraphPad Software Inc., San Diego, CA, USA).

\section{Results}

Patient characteristics. Seventeen patients were included in our study (Figure 1A), eleven in group A (patients with evolution of the disease after induction chemotherapy or persistent $\mathrm{N} 2+$ on pathological examination after surgical resection) and six in group $\mathrm{B}$ (patients with down-staging disease after induction therapy). The cohort average age was $61.7 \pm 9.2$ years $(60.2 \pm 10.4$ years for group A and $64.2 \pm 6.0$ years for group B, $p=0.42$, Mann-Whitney test). In total, ten male and seven female patients were analyzed, five male and six female patients in group A and five male and one female patient in group B ( $p=0.3$, Fisher's exact test) (Figure 1B).

Identification of SNPS that associate with response to therapy in NSCLC stage IIIA (N2). Single-nucleotide polymorphisms (SNPs) are a source of human genetic variation, and pharmacogenetic studies have revealed that 

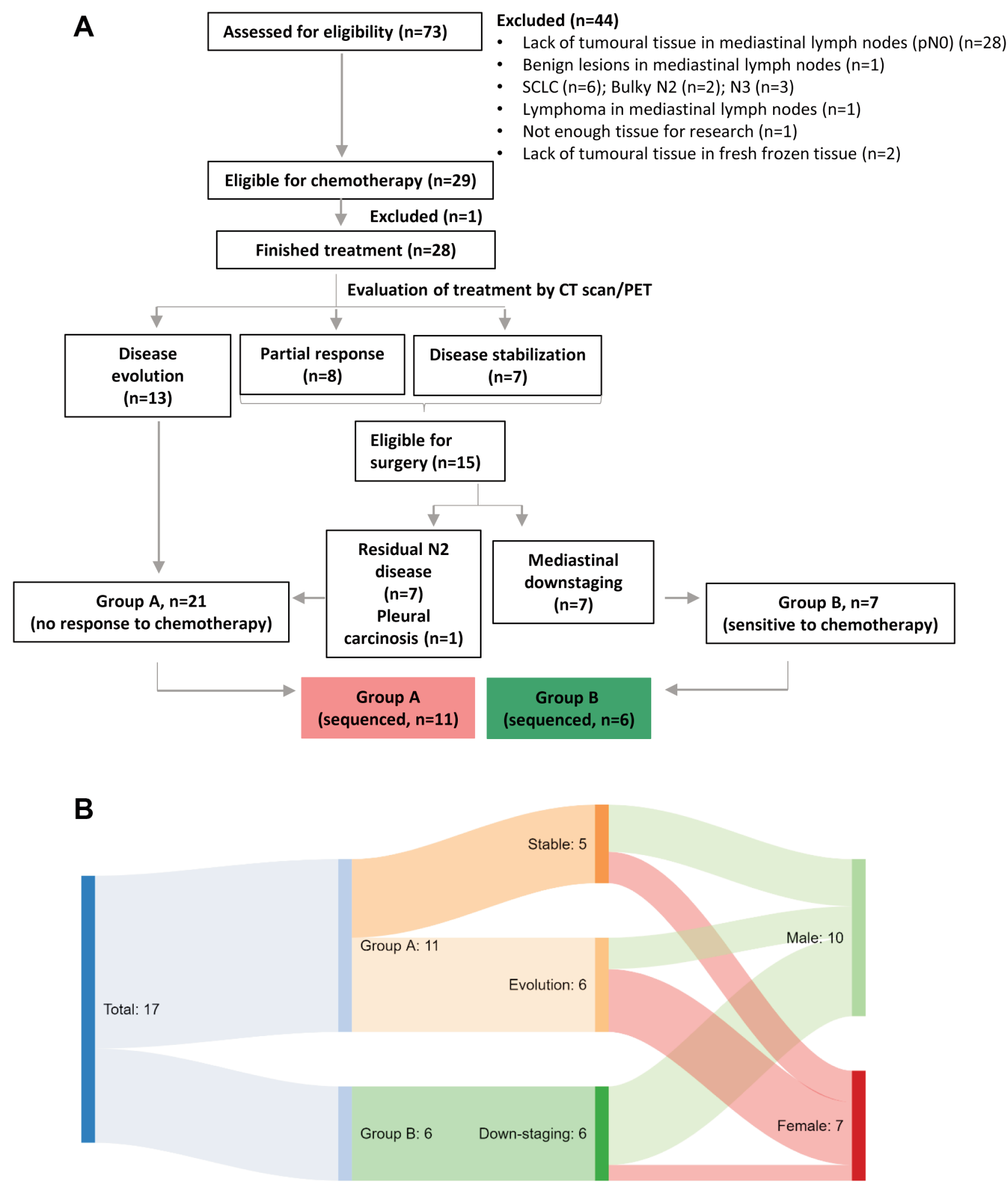

Figure 1. (A) Study workflow showing number of patients in each group and exclusion reasons. (B) Diagram showing patient distribution in response groups, type of response to treatment and gender (http://sankeymatic.com). 

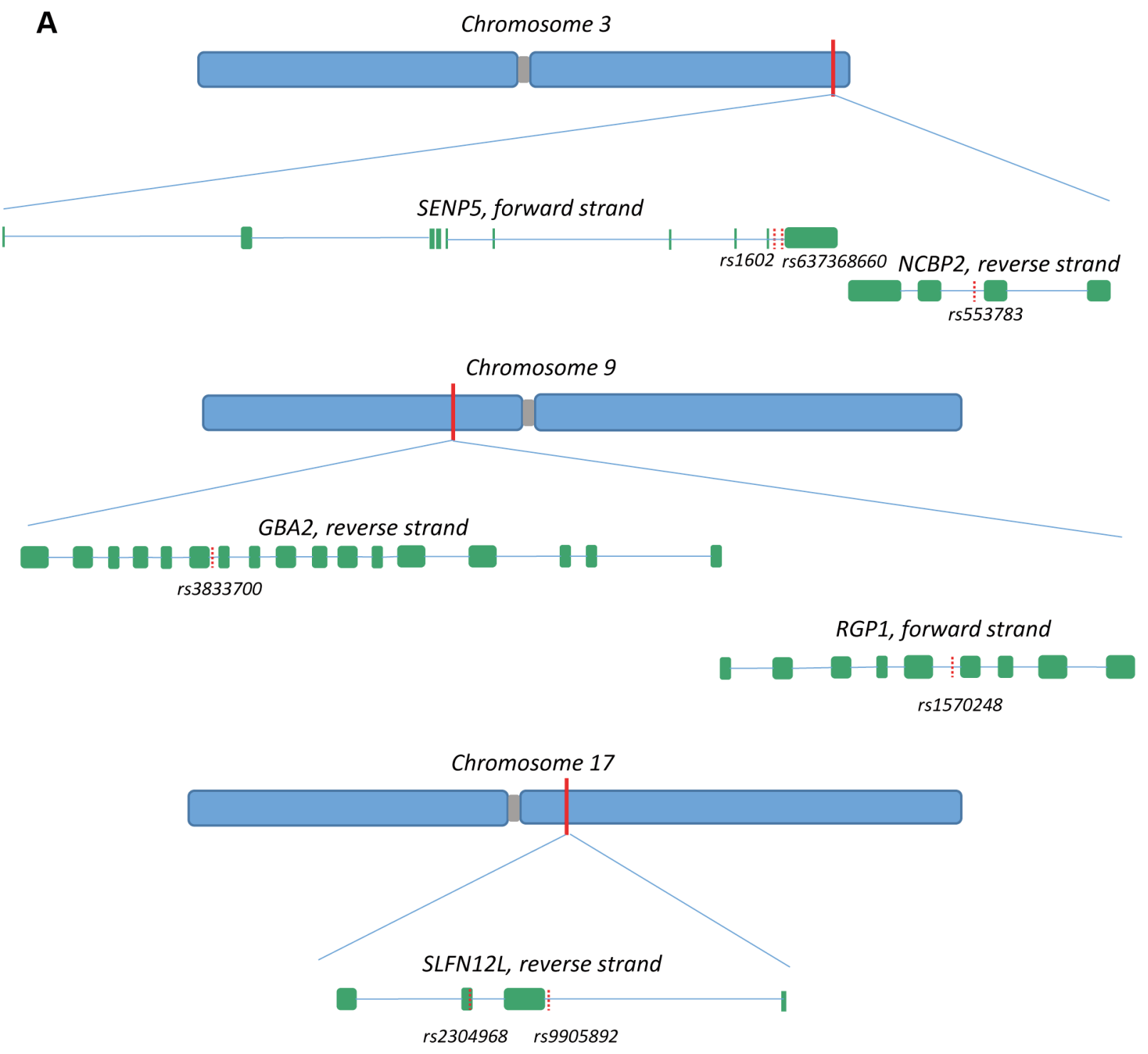

B

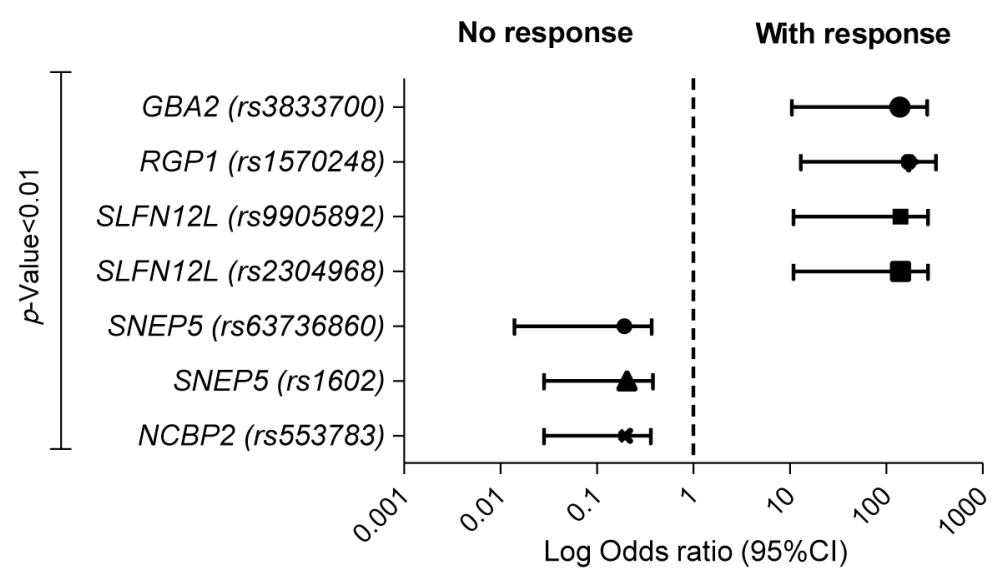

Figure 2. Continued 


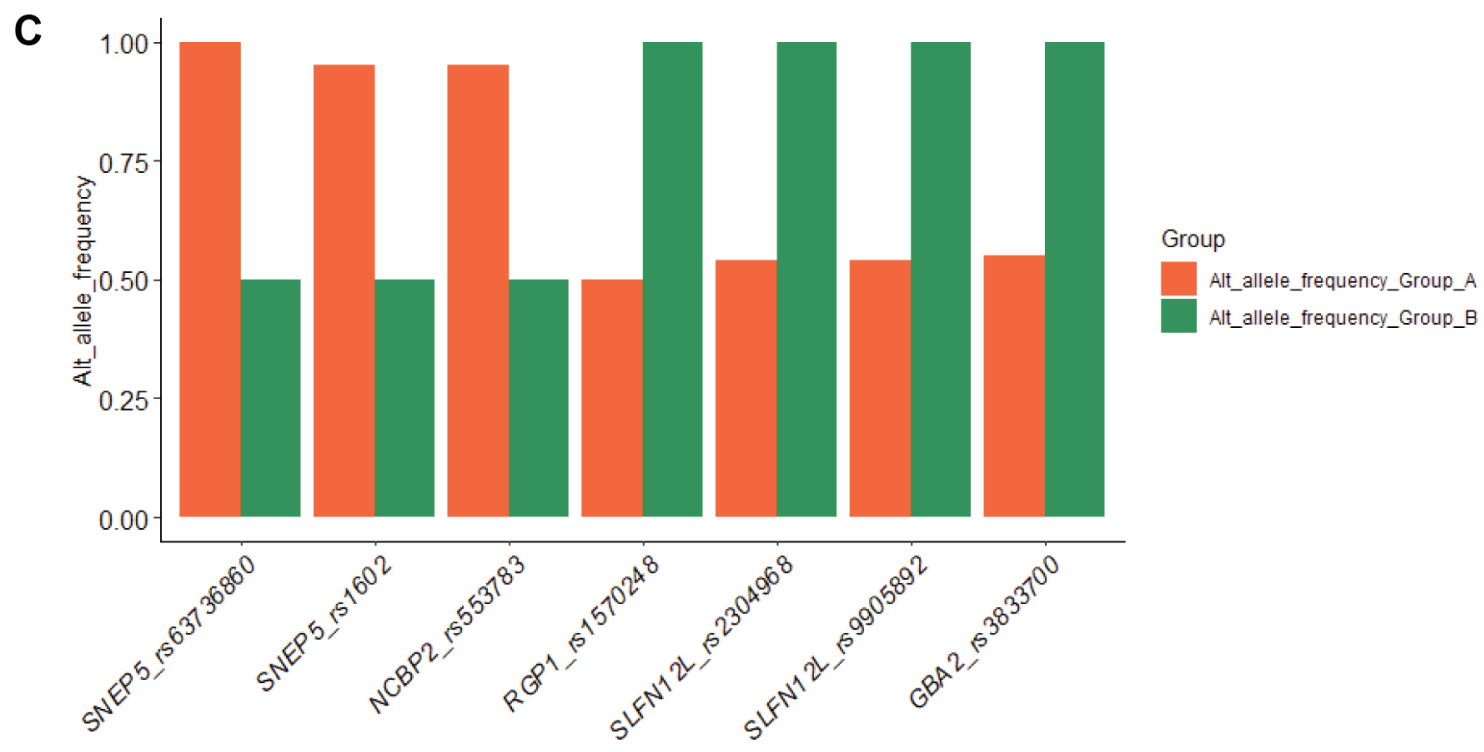

Figure 2. Analysis of SNPs associated with response: (A) Graphical representation of the seven SNPs identified and their location on chromosomes and genes (graph sizes do not take into account real sizes); (B) Forest plot of top 5 five genes altered between Group A (non-responders) and Group $B$ (responders) at $p<0.01 ;(C)$ Alternative allele frequency of the statistically significant SNPs $(p<0.01)$ between non-responders $($ Group A) and responders (Group B).

Table II. Seven statistically significant SNPs ( $p<0.01$; bold) identified in the "non-responders" group, group A, and "responders" group, group B. SNPs in ROS1 and POLE (last two rows) were identified among significant genomic variations when the threshold for analysis was set to $p<0.05$.

\begin{tabular}{|c|c|c|c|c|c|c|c|c|c|c|c|c|c|c|}
\hline \#CHROM & POS & ID & REF & ALT & $\begin{array}{c}\text { Group A } \\
\text { (Ref_- } \\
\text { allele) }\end{array}$ & $\begin{array}{c}\text { Group A } \\
\text { (Alt_- } \\
\text { allele) }\end{array}$ & $\begin{array}{c}\text { Group A } \\
\text { (Alt_- } \\
\text { freq) }\end{array}$ & $\begin{array}{l}\text { No. of } \\
\text { sample } \\
\text { w/mut }\end{array}$ & $\begin{array}{c}\text { Group B } \\
\text { (Ref_- } \\
\text { allele) }\end{array}$ & $\begin{array}{c}\text { Group B } \\
\text { (Alt__ } \\
\text { allele) }\end{array}$ & $\begin{array}{c}\text { Group B } \\
\text { (Alt_- } \\
\text { freq) }\end{array}$ & $\begin{array}{l}\text { No. of } \\
\text { sample } \\
\text { w/mut }\end{array}$ & $\begin{array}{l}\text { Fisher's } \\
p \text {-Value }\end{array}$ & Genes \\
\hline $\operatorname{chr} 3$ & 196657670 & rs63736860 & CT & C & $\mathbf{0}$ & 18 & 1.0 & 9 & 6 & 6 & 1 & 6 & 0.002 & SENP5 \\
\hline chr9 & 35751221 & rs1570248 & C & $\mathbf{T}$ & 9 & 9 & 0.5 & 9 & $\mathbf{0}$ & 12 & 1 & 6 & 0.004 & $R G P 1$ \\
\hline chr3 & 196666059 & rs553783 & A & G & 1 & 19 & 0.95 & 10 & 6 & 6 & 1 & 6 & 0.006 & NCBP2 \\
\hline chr17 & 33805150 & rs2304968 & $\mathbf{T}$ & C & 10 & 12 & 0.54 & 11 & $\mathbf{0}$ & 12 & 1 & 6 & 0.006 & SLFN12L \\
\hline chr17 & 33807250 & rs9905892 & $\mathbf{T}$ & $\mathbf{A}$ & 10 & 12 & 0.54 & 11 & 0 & 12 & 1 & 6 & 0.006 & SLFN12L \\
\hline $\operatorname{chr} 3$ & 196656772 & rs1602 & $\mathbf{G}$ & $\mathbf{A}$ & 1 & 19 & 0.95 & 10 & 5 & 5 & 0.5 & 5 & 0.009 & SENP5 \\
\hline chr9 & 35739115 & rs3833700 & G & GC & 8 & 10 & 0.55 & 9 & 0 & 12 & 1 & 6 & 0.010 & GBA2 \\
\hline chr6 & 117724499 & rs 1407179 & A & $\mathrm{C}$ & 0 & 12 & 1.0 & 6 & 4 & 4 & 1 & 4 & 0.014 & ROS1 \\
\hline chr12 & 133252796 & rs 4077170 & $\mathrm{C}$ & G & 6 & 10 & 0.6 & 8 & 0 & 12 & 1 & 6 & 0.024 & POLE \\
\hline
\end{tabular}

SNPs could influence the pharmacokinetics of the drugs and impact patients' response to treatment (7), proving their importance in drug selection process. Analysis of WES data between non-responders (group A) and responders (group B) to chemotherapy led to identification of 216 variants $(p<0.05$, Fisher's exact test) that segregated between the two groups. By lowering the $p$ to 0.01 , seven polymorphism in five genes were selected to be strong predictors of response: Sentrin/SUMO-specific peptidase 5 (SENP5), rs63736860 $(\mathrm{OR}=0.027, \quad 95 \% \mathrm{CI}=0.0013-0.55, \quad p=0.0016), \quad \mathrm{rs} 1602$ $(\mathrm{OR}=0.052,95 \% \mathrm{CI}=0.005-0.56, p=0.009)$ and nuclear cap- binding protein subunit $2(N C B P 2)$, rs553783 (OR=0.0052, $95 \% \mathrm{CI}=0.005-0.53, p=0.006)$ gene variants had a higher alternative allele frequency in non-responder group, while RGP1 homolog, RAB6A GEF complex partner 1 ( $R G P 1)$, rs $1570248(\mathrm{OR}=25,95 \% \mathrm{CI}=1.28-485.9, p=0.004)$, Schlafen family member 12 (SLFN12L), rs2304968 (OR=21, 95\% CI=1.11-398.9, $\quad p=0.006), \quad$ rs9905892 $\quad(\mathrm{OR}=21$, $95 \% \mathrm{CI}=1.11-398.9, p=0.006)$ and glucosylceramidase beta 2 $(G B A 2), r s 3833700(\mathrm{OR}=20.24,95 \% \mathrm{CI}=1.04-393.9, p=0.01)$ gene variants had a higher alternative allele frequency in responder group (Figure 2A, B and C and Table II). 
Analysis of linkage disequilibrium for the markers located on the same chromosome (chromosomes 3, 9 and 17), showed a strong association between pairs of SNPs in European populations, thus suggesting a lack of genetic recombination and their co-inheritance (Figure 3A, B and C).

Among all the 216 SNPs (that were statistically significant, $p<0.05)$, 64 were predicted to affect an exon, with two of those predicted to be frameshift variants: rs34595082, MRPS34 ( $p=0.028)$ and rs11467417, DEFB 126 ( $p=0.035$ ). The rest were either missense, affecting the 3 ' or 5'UTR sequence of the gene or were synonymous mutations.

Searching for variants in previously reported cancer genes among the 216 SNPs, we identified rs1407179 in ROS1 gene, an intronic variant that was more frequent in group A, and thus predicting a negative response to therapy $(p=0.0144)$ and rs4077170 in POLE that predicted a favorable response to therapy $(p=0.0237)$ (Table II).

\section{Discussion}

NSCLC is the most common type of lung cancer and the leading cause of oncological death among men and women worldwide $(8,9)$. It comprises of two histological subtypes: adenocarcinoma, squamous cell carcinoma, with adenocarcinoma subtype being the most widely diagnosed, representing about $40 \%$ of cases (10). Smoking is the major risk factor for the disease (11) that acts by inducing DNA damage and increasing the risk for accumulation of driver mutations in cancer genes (12), most notably the $\mathrm{C}>\mathrm{A}(\mathrm{G}>\mathrm{T})$ transversion in the TP53 gene (13) located on the nontranscribed strand. Nevertheless, patients that were never smokers might develop the disease probably due to other environmental exposures. Research in NSCLC facilitated an improved understanding of the molecular mechanisms that lead to the onset and development of the disease that reflected in a better therapeutic management (14). About two-sixths of NSCLC patients harbor a targetable oncogenic addiction that makes them candidates to targeted therapy (14), but the other patients, without evident alterations will be treated with firstline standard platinum-based chemotherapy. Even so, tumors that initially have a targetable alteration will develop resistance and so the response rate of the patients will be modest.

Patients with NSCLC stage IIIA, with invasion of mediastinal lymph nodes (N2), represent a heterogenous prognostic category of patients. Bulky N2 or functionally impaired patients will not be eligible for surgery, but for the rest of $\mathrm{N} 2$ patients, a treatment by induction chemotherapy followed by surgical resection if the disease is at least stabilized, is the most adopted strategy. The patients who will be down-staged by the induction chemotherapy (no residual disease on the mediastinal lymph nodes after radical lymphadenectomy) are those who will benefit most from this strategy (15). The response to induction chemotherapy is one of the most important prognostic factors (16) for patients with NSCLC stage IIIA (N2), but it is currently impossible to predict this response.

In this study, we identified new markers (polymorphisms) that might predict response to therapy, in patients with NSCLC stage IIIA (N2) that were prospectively followed-up and had samples collected from mediastinal lymph nodes prior to chemotherapy, by using whole-exome sequencing.

We sequenced samples from seventeen patients and detected 216 SNPs that discriminated between responders and nonresponders to platinum therapy, at a $p<0.05$ by the Fischer's $t$ test. Seven of these polymorphisms segregated between nonresponder and responder patients with a $p<0.01$ and were located on chromosome 3 , in SENP5 and NCBP2 genes, chromosome 9 in RGP1 and GBA2 genes and chromosome 17, SLFN12L gene. To the best of our knowledge, these polymorphisms have not been described before as being associated with response to therapy of NSCLC patients.

Sentrin/SUMO-specific peptidases 5 (SENP5) belongs to a family of peptidases involved in maturation of small ubiquitin-like modifiers (SUMO) residues and their removal (17) from protein targets. SUMOylation/deSUMOylation are post-translational modifications (PMT) that can regulate biological processes like DNA damage, immune response, apoptosis and tumorigenesis $(18,19)$ as well as $\mathrm{T}$ cell activation and differentiations (20). SENP5 has C-terminal hydrolase and isopeptidase activities and an important role in mitosis (21). It shares sequence and substrate homology with SENP3 both being located in the nucleolus and usually classified as a subfamily of SENP proteins (22-24). SENP5 was identified as a candidate driver gene at the locus 3q2629 in squamous cell carcinoma of the lung, a type of NSCLC, together with SENP2, DCUN1D1 and DVL3 (25), this whole region being a biomarker of differentiation between different histological subtypes of NSCLC (26). SENP5 is mapped at $3 \mathrm{q} 29$ locus that was suggested to be a susceptibility region in NSCLC $(27,28)$. Amplification of the distal regions of $3 \mathrm{q}$, including $3 \mathrm{q} 29$ is considered a parameter of neoplastic transformation in lung cancer (29).

In hepatocellular carcinoma, drug activation of SENP5 inhibited hypoxia that has been shown to be link to resistance to chemotherapy in part by activation of the Sonic Hedgehog (SHH) pathway (30). Nuclear cap-binding protein subunit 2 (NCBP2) component of the nuclear cap-binding protein complex (CBC) was identified as a target gene of miR-193a$5 \mathrm{p}$ in lung cancer (31). In prostate cancer, silencing of miR193a-5p increased sensitivity to docetaxel (32), suggesting a possible new possible therapeutic approach.

Schlafen family member 12-like $(S L F N 12 L)$ is a human Schlafen protein that was reported to promote differentiation in human prostate cancer and is known to be down-regulated during $\mathrm{T}$ cell activation and up-regulated by type I interferons (IFNs) $(33,34)$. 

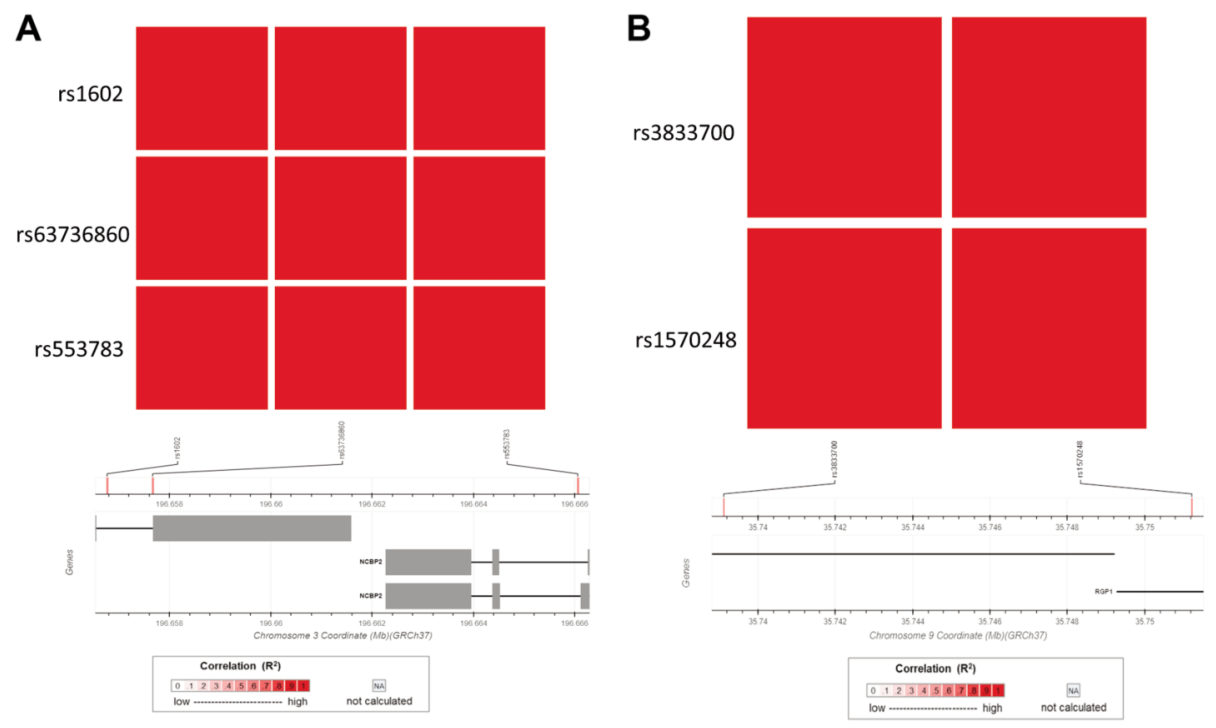

\begin{tabular}{|c|c|c|c|c|c|c|}
\hline \multirow{2}{*}{$\begin{array}{l}\text { Rs number } \\
\left(D^{\prime} / R^{2}\right)\end{array}$} & \multirow[t]{2}{*}{ rs1602 } & \multirow[t]{2}{*}{ rs63736860 } & \multirow{2}{*}{ rs553783 } & & & \multirow{3}{*}{ rs1570278 } \\
\hline & & & & \multirow{2}{*}{$\begin{array}{l}\text { Rs number } \\
\left(D^{\prime} / R^{2}\right)\end{array}$} & \multirow{2}{*}{ rs3833700 } & \\
\hline rs1602 & $1 / 1$ & $1 / 0.989$ & $0.978 / 0.94$ & & & \\
\hline rs6373686 & $1 / 0.989$ & $1 / 1$ & $0.972 / 0.94$ & \multirow{3}{*}{$\begin{array}{l}\text { rs3833700 } \\
\text { rs1570248 }\end{array}$} & $1 / 1$ & $1 / 1$ \\
\hline 0 & & & & & \multirow[t]{2}{*}{$1 / 1$} & \multirow[t]{2}{*}{$1 / 1$} \\
\hline rs553783 & $0.978 / 0.94$ & $0.972 / 0.94$ & $1 / 1$ & & & \\
\hline
\end{tabular}

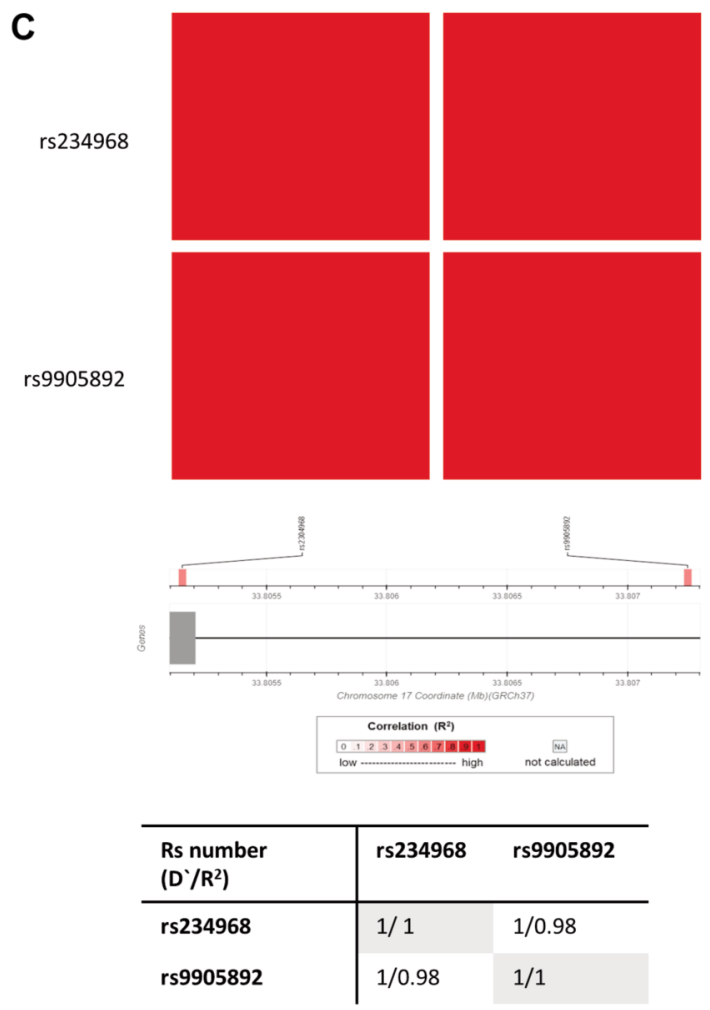

Figure 3. Heatmap matrix of pairwise linkage disequilibrium in 5 European populations for SNPs on chromosome 3 (A); chromosome 9 (B) and chromosome $17(C)$ (heatmaps and D' and R2 were generated using the LDmatrix module from LDlink (6); the shade of red represents the degree of linkage disequilibrium between the pairs. 
Glucosylceramidase beta 2 (GBA2) non-lysosomal glucosylceramidase catalyzes the hydrolysis of glucosylceramide (GlcCer) to free glucose and ceramide (34). Mutations are associated with the progression of neurological disorders (35). It is highly expressed in the liver and mutations were associated with deficient liver regeneration mainly due to changes in STAT3 signaling pathway (36). RGP1 homolog, RAB6A GEF complex partner 1 (RGP1) together with RIC1 forms a complex that acts as a guanine nucleotide exchange factor (GEF), which activates RAB6A by exchanging bound GDP for free GTP and may thereby be required for efficient fusion of endosome-derived vesicles with the Golgi compartment (37).

Although limited in sample size, mainly due to the complexity of the disease and difficulty of achieving longitudinal samples, our study identified variants that might be important in the therapy selection process. It also accentuates on the essential role of inter-individual variability associated with chemotherapy response in NSCLC stage IIIA (N2) patients and supports the need of more similar studies, on bigger cohorts, to be undertaken.

\section{Conflicts of Interest}

The Authors declare no conflicts of interest.

\section{Authors' Contributions}

AN processed the samples, extracted DNA, assessed sample's quality, prepared samples for shipping and analyzed the results received from BGI; AL and DD were involved in histopathological review of the samples; VL was involved in sample processing; SD, IP and MG were involved in the implementation and coordination of the study; WK, MA and EC were involved in sample collection, MG conceived the study, AN and MG wrote the manuscript with the assistance and final approval of all Authors.

\section{Acknowledgements}

The research presented in this article was supported by Funding Contract no. 211 with OI - ANCS signed on 20.07.2010, within POS CE Operational Programme, Priority Axis 2 - CDI competitiveness - Major Field of Intervention D.2.1. "Researchdevelopment in partnerships between research-development universities/institutes and enterprises for result attainment applicable in economy", Operation 2.1.2.: "High level scientific CD projects with specialists from abroad", Project title Gene Profile Of NonSmall Cell Primitive Bronchopulmonary Cancers And Invasion Of Mediastinal Lymph Nodes, Project number/Code SMIS 692/12650, undertaken between 20.07.2010 - 30.06.2014.

\section{References}

1 Wood DE: National comprehensive cancer network (NCCN) clinical practice guidelines for lung cancer screening. Thorac Surg Clin 25(2): 185-197, 2015. PMID: 25901562. DOI: $10.1016 /$ j.thorsurg .2014 .12 .003
2 Gray JE, Villegas A, Daniel D, Vicente D, Murakami S, Hui R, Kurata T, Chiappori A, Lee KH, Cho BC, Planchard D, Paz-Ares L, Faivre-Finn C, Vansteenkiste JF, Spigel DR, Wadsworth C, Taboada M, Dennis PA, Ozguroglu M and Antonia SJ: Three-year overall survival with durvalumab after chemoradiotherapy in stage III NSCLC-update from pacific. J Thorac Oncol 15(2): 288-293, 2020. PMID: 31622733. DOI: 10.1016/j.jtho.2019.10.002

3 Santana-Davila R, Szabo A, Arce-Lara C, Williams CD, Kelley MJ and Whittle J: Cisplatin versus carboplatin-based regimens for the treatment of patients with metastatic lung cancer. An analysis of veterans health administration data. J Thorac Oncol 9(5): 702-709, 2014. PMID: 24662458. DOI: 10.1097/JTO.0000000000000146

4 Goodsell DS: The molecular perspective: Cisplatin. Oncologist 11(3): 316-317, 2006. PMID: 16549816. DOI: 10.1634/ theoncologist.11-3-316

5 Grigoroiu M, Tagett R, Draghici S, Dima S, Nastase A, Florea R, Sorop A, Ilie V, Bacalbasa N, Tica V, Laszlo V, Mansuet-Lupo A, Damotte D, Klepetko W, Popescu I and Regnard JF: Geneexpression profiling in non-small cell lung cancer with invasion of mediastinal lymph nodes for prognosis evaluation. Cancer Genomics Proteomics 12(5): 231-242, 2015. PMID: 26417026.

6 Machiela MJ and Chanock SJ: Ldlink: A web-based application for exploring population-specific haplotype structure and linking correlated alleles of possible functional variants. Bioinformatics 31(21): 3555-3557, 2015. PMID: 26139635. DOI: 10.1093/ bioinformatics/btv 402

7 Sun N, Sun X, Chen B, Cheng H, Feng J, Cheng L and Lu Z: MRP2 and Gstp1 polymorphisms and chemotherapy response in advanced non-small cell lung cancer. Cancer Chemother Pharmacol 65(3): 437-446, 2010. PMID: 19568750. DOI: 10.1007/s00280-009-1046-1

8 Ferlay J, Colombet M, Soerjomataram I, Mathers C, Parkin DM, Pineros M, Znaor A and Bray F: Estimating the global cancer incidence and mortality in 2018: Globocan sources and methods. Int J Cancer 144(8): 1941-1953, 2019. PMID: 30350310. DOI: 10.1002/ijc. 31937

9 Molina JR, Yang P, Cassivi SD, Schild SE and Adjei AA: Nonsmall cell lung cancer: Epidemiology, risk factors, treatment, and survivorship. Mayo Clin Proc 83(5): 584-594, 2008. PMID: 18452692. DOI: $10.4065 / 83.5 .584$

10 Zappa C and Mousa SA: Non-small cell lung cancer: Current treatment and future advances. Transl Lung Cancer Res 5(3): 288-300, 2016. PMID: 27413711. DOI: 10.21037/tlcr.2016.06.07

11 Cheng TY, Cramb SM, Baade PD, Youlden DR, Nwogu C and Reid ME: The international epidemiology of lung cancer: Latest trends, disparities, and tumor characteristics. J Thorac Oncol 11(10): 16531671, 2016. PMID: 27364315. DOI: 10.1016/j.jtho.2016.05.021

12 Alexandrov LB, Ju YS, Haase K, Van Loo P, Martincorena I, Nik-Zainal S, Totoki Y, Fujimoto A, Nakagawa H, Shibata T, Campbell PJ, Vineis P, Phillips DH and Stratton MR: Mutational signatures associated with tobacco smoking in human cancer. Science 354(6312): 618-622, 2016. PMID: 27811275. DOI: 10.1126/science.aag0299

13 Alexandrov LB, Nik-Zainal S, Wedge DC, Campbell PJ and Stratton MR: Deciphering signatures of mutational processes operative in human cancer. Cell Rep 3(1): 246-259, 2013. PMID: 23318258. DOI: 10.1016/j.celrep.2012.12.008

14 Rotow J and Bivona TG: Understanding and targeting resistance mechanisms in NSCLC. Nat Rev Cancer 17(11): 637-658, 2017. PMID: 29068003. DOI: 10.1038/nrc.2017.84 
15 Marulli G, Verderi E, Zuin A, Schiavon M, Battistella L, Perissinotto E, Romanello P, Favaretto AG, Pasello G and Rea F: Outcomes and prognostic factors of non-small-cell lung cancer with lymph node involvement treated with induction treatment and surgical resection. Interact Cardiovasc Thorac Surg 19(2): 256-262; discussion 262, 2014. PMID: 24824495. DOI: 10.1093/icvts/ivu141

16 Betticher DC, Hsu Schmitz SF, Totsch M, Hansen E, Joss C, von Briel C, Schmid RA, Pless M, Habicht J, Roth AD, Spiliopoulos A, Stahel R, Weder W, Stupp R, Egli F, Furrer M, Honegger H, Wernli M, Cerny T, Ris HB and Swiss Group for Clinical Cancer $\mathrm{R}$ : Prognostic factors affecting long-term outcomes in patients with resected stage IIIa pN2 non-small-cell lung cancer: 5-year follow-up of a phase II study. Br J Cancer 94(8): 1099-1106, 2006. PMID: 16622435. DOI: 10.1038/sj.bjc.6603075

$17 \mathrm{Kim} \mathrm{JH}$ and Baek SH: Emerging roles of desumoylating enzymes. Biochim Biophys Acta 1792(3): 155-162, 2009. PMID: 19162180. DOI: 10.1016/j.bbadis.2008.12.008

18 Han ZJ, Feng YH, Gu BH, Li YM and Chen H: The posttranslational modification, SUMOylation, and cancer (review). Int J Oncol 52(4): 1081-1094, 2018. PMID: 29484374. DOI: $10.3892 /$ ijo. 2018.4280

19 Bettermann K, Benesch M, Weis S and Haybaeck J: Sumoylation in carcinogenesis. Cancer Lett 316(2): 113-125, 2012. PMID: 22138131. DOI: 10.1016/j.canlet.2011.10.036

20 Yu X, Lao Y, Teng XL, Li S, Zhou Y, Wang F, Guo X, Deng S, Chang Y, Wu X, Liu Z, Chen L, Lu LM, Cheng J, Li B, Su B, Jiang J, Li HB, Huang C, Yi J and Zou Q: SENP3 maintains the stability and function of regulatory $\mathrm{T}$ cells via $\mathrm{BACH} 2$ deSUMOylation. Nat Commun 9(1): 3157, 2018. PMID: 30089837. DOI: 10.1038/s41467-018-05676-6

21 Di Bacco A, Ouyang J, Lee HY, Catic A, Ploegh H and Gill G: The SUMO-specific protease SENP5 is required for cell division. Mol Cell Biol 26(12): 4489-4498, 2006. PMID: 16738315. DOI: $10.1128 / \mathrm{MCB} .02301-05$

$22 \mathrm{Hu} \mathrm{C}$ and Jiang X: The sumo-specific protease family regulates cancer cell radiosensitivity. Biomed Pharmacother 109: 66-70, 2019. PMID: 30396093. DOI: 10.1016/j.biopha.2018.10.071

23 Gong L and Yeh ET: Characterization of a family of nucleolar SUMO-specific proteases with preference for SUMO-2 or SUMO-3. J Biol Chem 281(23): 15869-15877, 2006. PMID: 16608850. DOI: $10.1074 /$ jbc.M511658200

24 Hattersley N, Shen L, Jaffray EG and Hay RT: The sumo protease SENP6 is a direct regulator of pml nuclear bodies. Mol Biol Cell 22(1): 78-90, 2011. PMID: 21148299. DOI: 10.1091/mbc.E10-06-0504

25 Wang J, Qian J, Hoeksema MD, Zou Y, Espinosa AV, Rahman SM, Zhang B and Massion PP: Integrative genomics analysis identifies candidate drivers at 3q26-29 amplicon in squamous cell carcinoma of the lung. Clin Cancer Res 19(20): 5580-5590, 2013. PMID: 23908357. DOI: 10.1158/1078-0432.CCR-13-0594

26 Pikor LA, Ramnarine VR, Lam S and Lam WL: Genetic alterations defining NSCLC subtypes and their therapeutic implications. Lung Cancer 82(2): 179-189, 2013. PMID: 24011633. DOI: 10.1016/j.lungcan.2013.07.025

27 Yoon KA, Park JH, Han J, Park S, Lee GK, Han JY, Zo JI, Kim J, Lee JE, Takahashi A, Kubo M, Nakamura Y and Lee JS: A genome-wide association study reveals susceptibility variants for non-small cell lung cancer in the korean population. Hum Mol Genet 19(24): 4948-4954, 2010. PMID: 20876614. DOI: $10.1093 / \mathrm{hmg} / \mathrm{ddq} 421$
28 Zhang Y, Gu C, Shi H, Zhang A, Kong X, Bao W, Deng D, Ren $\mathrm{L}$ and $\mathrm{Gu} \mathrm{D}$ : Association between C3orf21, TP63 polymorphisms and environment and NSCLC in never-smoking chinese population. Gene 497(1): 93-97, 2012. PMID: 22310392. DOI: $10.1016 /$ j.gene.2012.01.053

29 Qian J and Massion PP: Role of chromosome 3q amplification in lung cancer. J Thorac Oncol 3(3): 212-215, 2008. PMID: 18317062. DOI: $10.1097 / J T O .0 b 013 e 3181663544$

30 Zhang CY, Jiang ZM, Ma XF, Li Y, Liu XZ, Li LL, Wu WH and Wang T: Saikosaponin-d inhibits the hepatoma cells and enhances chemosensitivity through SENP5-dependent inhibition of Gli1 SUMOylation under hypoxia. Front Pharmacol 10: 1039, 2019. PMID: 31616295. DOI: 10.3389/fphar.2019.01039

31 Xie ZC, Tang RX, Gao X, Xie QN, Lin JY, Chen G and Li ZY: A meta-analysis and bioinformatics exploration of the diagnostic value and molecular mechanism of mir-193a-5p in lung cancer. Oncol Lett 16(4): 4114-4128, 2018. PMID: 30250529. DOI: 10.3892/ol.2018.9174

32 Yang Z, Chen JS, Wen JK, Gao HT, Zheng B, Qu CB, Liu KL, Zhang ML, Gu JF, Li JD, Zhang YP, Li W, Wang XL and Zhang Y: Silencing of mir-193a-5p increases the chemosensitivity of prostate cancer cells to docetaxel. J Exp Clin Cancer Res 36(1): 178, 2017. PMID: 29216925. DOI: 10.1186/s13046-017-0649-3

33 Kovalenko PL and Basson MD: Schlafen 12 expression modulates prostate cancer cell differentiation. J Surg Res 190(1): 177-184, 2014. PMID: 24768141. DOI: 10.1016/j.jss.2014.03.069

34 Puck A, Aigner R, Modak M, Cejka P, Blaas D and Stockl J: Expression and regulation of schlafen (SLFN) family members in primary human monocytes, monocyte-derived dendritic cells and $t$ cells. Results Immunol 5: 23-32, 2015. PMID: 26623250. DOI: $10.1016 /$ j.rinim.2015.10.001

35 Malekkou A, Samarani M, Drousiotou A, Votsi C, Sonnino S, Pantzaris M, Chiricozzi E, Zamba-Papanicolaou E, Aureli M, Loberto $\mathrm{N}$ and Christodoulou K: Biochemical characterization of the GBA2 c.1780 $\mathrm{g}>\mathrm{c}$ missense mutation in lymphoblastoid cells from patients with spastic ataxia. Int J Mol Sci 19(10), 2018. PMID: 30308956. DOI: 10.3390/ijms 19103099

36 Gonzalez-Carmona MA, Sandhoff R, Tacke F, Vogt A, Weber S, Canbay AE, Rogler G, Sauerbruch T, Lammert F and Yildiz Y: Beta-glucosidase 2 knockout mice with increased glucosylceramide show impaired liver regeneration. Liver Int 32(9): 1354-1362, 2012. PMID: 22764777. DOI: 10.1111/j.1478-3231.2012.02841.x

37 Pusapati GV, Luchetti G and Pfeffer SR: Ric1-Rgp1 complex is a guanine nucleotide exchange factor for the late golgi rab6a gtpase and an effector of the medial golgi rab33b gtpase. J Biol Chem 287(50): 42129-42137, 2012. PMID: 23091056. DOI: 10.1074/jbc.M112.414565
Received May 30, 2020

Revised June 21, 2020

Accepted June 22, 2020 